\title{
A New Esterase Amplification Involved in OP Resistance in Culex Pipiens Mosquitoes from Tunisia
}

\author{
Ahmed Tabbabi*, Jaber Daaboub, Rhim Adel, Laamari Ali, Hassen Ben Cheikh \\ Laboratoire de Génétique, Faculté de Médecine de Monastir, Université de Monastir, 5019 Monastir, Tunisia
}

Received: March 24, 2016; Accepted: May 06, 2016; Published: May 11, 2016

*Corresponding author: Ahmed Tabbabi, Laboratoire de Génétique, Faculté de Médecine de Monastir, Université de Monastir, 5019 Monastir, Tunisia, E-mail ID: tabbabiahmed@gmail.com

\begin{abstract}
The super-locus Ester is one of the two genome areas in the mosquito Culex pipiens involved in Organophosphorus (OP) insecticide resistance. Resistance to the organophosphate chlorpyrifos was investigated in one population of Culex pipiens collected in northwestern Tunisia. High Resistance to chlorpyrifos was observed and new esterases were detected. These results must be considered in future mosquito control programs, since detected esterases can lead to high resistance to several organophosphorus insecticides.
\end{abstract}

Keywords: Culex pipiens; Tunisia; High resistance; Chlorpyrifos; New esterases

\section{Introduction}

In most parts of Tunisia, mosquitoes have been subjected to Organophosphate (OP) insecticide treatments since the mid1960s, and resistance gene monitoring in the Culex pipiens complex (Diptera: Culicidae) started in only a few locations from the end of the 1980s. The super-locus Ester is one of the two genome areas in the mosquito Culex pipiens involved in Organophosphorus (OP) insecticide resistance [1,2]. This super-locus is composed of two loci, Est- 3 and Est-2, and both loci encode for detoxifying esterase. The resistance mechanism at Ester corresponds to an esterase over-production at one or both loci $[2,3-5]$. This study was conducted in order to address the following points: what is the resistance status in Tunisia populations of the Culex pipiens with regard to Chlorpyrifos insecticides and which resistance genes are involved?

\section{Materials \& Methods}

Culex pipiens were collected as larvae and pupae in the Governorate of Jendouba, northern Tunisia, in 2004. Resistance characteristics of larval natural populations were determined by bioassays on fourth instar larvae, following the method described in Raymond M, et al. [6] (Five replicates per dose and 100 insects per dose). Reference strains used were S-LAB, an insecticides susceptible strain without any known resistance genes [7]. Chlorpyrifos insecticides (OP) were used in ethanol solutions.
Mortality data were analyzed by the log-probit program of Raymond M [8], based on Finney, [9]. Esterase phenotypes were established by starch electrophoresis (TME 7.4 buffer system) as described by Pasteur, et al. $[10,11]$ using homogenates of thorax and abdomen. Acetylcholinesterase (AChE) phenotypes were determined according to bioassays using tests with propoxur.

\section{Results}

The linearity of dose-mortality responses was accepted (Chi square analysis $P>0.05$ ) for S-Lab and Jendouba population (slope regression is 3.42 for S-Lab with Heterogeneity factor equal to 1 and 2.15 for Jendouba population with Heterogeneity factor equal to 5.01). RR at LC50 (RR50) showed that the sample was resistant to chlorpyrifos. The RR50 reached very high level with chlorpyrifos (RR50 = 8062 with confidence limits between 7759.46 and 8285.87). Addition of DEF to chlorpyrifos bioassays did not decrease tolerance significantly $(P>0.05)$ in S-Lab and Jendouba sample. So, the increased detoxification by EST (and/ or glutathione-s-transferases) was not involved in chlorpyrifos resistance of this sample. However, as reported by Ben Cheikh, et al. [12] the mosquito Culex pipiens esterases contributed to OP resistance by their increased activity. Likewise AChE was not involved in chlorpyrifos resistance.

A total of 20 mosquitoes were analyzed. Starch gel electrophoresis didn't disclose any overproduced esterases in the Jendouba samples. Two new patterns (0.1\%) were observed (Figure 1). The first one (named New1 until further characterization) displayed under esterase A1 and between A4/ B4. The second (New2) displayed under esterase A1. New1 and New2 are two new resistant esterases and they are first detected in the present samples from 2004.

\section{Discussion}

Anew esterase, A13, characterized by the same electrophoretic migration as esterase A1 was identified in Tunisia by Ben Cheikh, et al. [13]. Many others new esterases were identified and dated vey old in the world [14]. Recently a resistant allele of an unknown gene (named T) linked to ace-2 genes were identified [2]. The new 


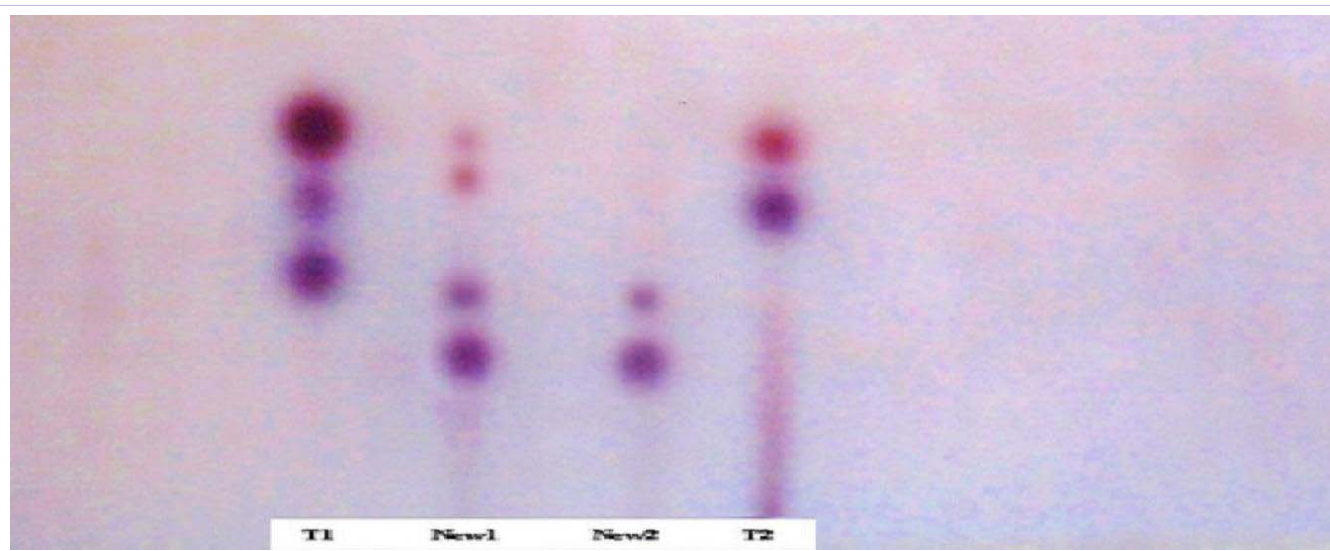

Figure 1: Activity esterases in single adults from the Jendouba sample analyzed on starch gels. The arrow indicates electrophoretic migration of the proteins. T1: A control mosquito displayed a phenotype with A2-B2/A4-B4 or A2-B2/A5-B5; T2: A control mosquito displayed a phenotype with A4B4 and/or A5 -B5; New1 and New2: new esterases.

overproduced esterases detected could be responsible, at least partly, for the OP resistance. In fact, theoretical studies showed that new alleles allow low rates of resistance compared to those already known [15]. These results must be considered in future mosquito control programs, since the detected esterases can lead to high resistance to several organophosphorus insecticides.

\section{Acknowledgments}

The authors thank to the medicine faculty of Monastir for the facilities provided in the development of this study.

\section{References}

1. Lenormand T, Guillemaud T, Bourguet D, Raymond M. Evaluating gene flow using selected markers: a case study. Genetics. 1998;149(3):138392.

2. Alout H, Labbé P, Berthomieu A, Makoundou P, Fort P, Pasteur $\mathrm{N}$, et al. High chlorpyrifos resistance in Culex pipiens mosquitoes: strong synergy between resistance genes. Heredity (Edinb). 2016;116(2):224-31. doi: 10.1038/hdy.2015.92

3. Raymond M, Chevillon C, Guillemaud T, Lenormand T, Pasteur $\mathrm{N}$. An overview of the evolution of overproduced esterases in the mosquito Culex pipiens. Philos Trans R Soc Lond B Biol Sci. 1998;353(1376):1707-11.

4. Osta MA, Rizk ZJ, Labbé P, Weill M, Knio K. Insecticide resistance to organophosphates in Culex pipiens complex from Lebanon. Parasit Vectors. 2012;5:132. doi: 10.1186/1756-3305-5-132.

5. Low VL, Chen CD, Lee HL, Tan TK, Chen CF, Leong CS, et al. Enzymatic characterization of insecticide resistance mechanisms in field populations of Malaysian Culex quinquefasciatus say (Diptera: Culicidae). PLoS One. 2013;8(11):e79928. doi: 10.1371/journal. pone.0079928.
6. Raymond M, Marquine M. Evolution of insecticide resistance in Culex pipiens populations: the Corsican paradox. Journal of Evolution Biology. 1994;7(3):315-337.

7. Georghiou GP, Metcalf RL, Gidden FE. Carbamate-resistance in mosquitos. Selection of Culex pipiens fatigans Wiedemann $(=C$. quinquefasciatus Say) for resistance to Baygon. Bull World Health Organ. 1966;35(5):691-708.

8. Raymond M. PROBIT CNRS-UMII. Licence L93019, Avenix, 24680 St. Georges d'Orques, France. 1993.

9. Finney DJ. Probit Analysis. Cambridge University Press, Cambridge, UK. 1971.

10. Pasteur N, Iseki A, Georghiou GP. Genetic and biochemical studies of the highly active esterases $\mathrm{A}^{\prime}$ and $\mathrm{B}$ associated with organophosphate resistance in mosquitoes of the Culex pipiens complex. Biochem Genet. 1981;19(9-10):909-19.

11. Pasteur N, Pasteur G, Bonhomme F, Britton-Davidian J, J Catalan. Practical Isozyme Genetics. Ellis Harwood, Chichester, UK. 1988.

12. Ben Cheikh R, Berticat C, Berthomieu A, Pasteur N, Ben Cheikh $\mathrm{H}$, Weill M. Characterization of a novel high-activity esterase in Tunisian populations of the mosquito Culex pipiens. J Econ Entomol. 2008;101(2):484-91.

13. Ben Cheikh R, Berticat C, Berthomieu A, Pasteur N, Ben Cheikh H, Weill M. Genes conferring resistance to organophosphorus insecticides in Culex pipiens (Diptera: Culicidae) from Tunisia. J Med Entomol. 2009;46(3):523-30.

14. Qiao CL, Sun ZQ, Liu JE. New esterase enzymes involved in organophosphate resistance in Culex pipiens (Diptera: Culicidae) from Guang Zhou, China. J Med Entomol. 1999;36(6):666-70.

15. Raymond M, Heckel DG, Scott JG. Interaction between pesticide genes: model and experiment. Genetics. 1989;123(3):543-51. 